\title{
Front End of Innovation: An Integrative Literature Review
}

\author{
Ariane Rodrigues Pereira ${ }^{1}$, João José Pinto Ferreira ${ }^{1,2}$ Alexandra Lopes ${ }^{3}$ \\ ${ }^{1}$ Faculty of Engineering, University of Porto, Department of Industrial Engineering and \\ Management, Porto, Portugal; Rua Dr. Roberto Frias, s/n 4200-465 Porto PORTUGAL \\ arianerpegmail.com \\ ${ }^{2}$ Institute for Systems and Computer Engineering, Technology and Science - INESC \\ TEC, Porto \\ jjpf@fe.up.pt \\ ${ }^{3}$ Faculty of Arts, University of Porto, Department of Sociology, Porto, Portugal \\ aslopes@letras.up.pt
}

\begin{abstract}
The beginning of the innovation process also known as Front End of Innovation (FEI) is an important contributor to the successful development of new products and the business success. The present study aims at giving an overview of how the FEI concept has been handled over the years, by identifying the focus of the research conducted in this domain knowledge. To this end, this study unfolds an encompassing perspective by developing an analysis of existing publications against two FEI Reference Models. This analysis comprised of the compilation, selection, and review of the content of 169 publications concerning the Front End of Innovation. The period of analysis covered all years until 2015. Evidence shows that this topic has received greater attention in the recent years both regarding depth and the number of publications. However, there are still pending gaps in the literature that are highlighted in this paper. The topics addressing organisational issues were the ones that received more attention.
\end{abstract}

Keywords. Innovation, Front-End of Innovation, FEI, Integrative Literature Review.

\section{Introduction}

Despite considerable investment in New Product Development (NPD), success rates of NPD are generally below 25\% (Evanschitzky et al., 2012). Any firm aiming at competing on innovation needs to be proficient in all phases of the NPD process (Khurana and Rosenthal, 1998). This process is typically divided into three phases: The Fuzzy Front End (FFE) ending with the so-called Concept Development, the New Product Development (NPD) process and the Commercialization (Koen et al., 2002). FFE is also known as Front End of Innovation (Martinsuo and Poskela, 2011). In this paper, we will use this term.

The early phase of innovation requires attention since it is recognised as an important driver of positive results for new products and for the overall success of the business (Kock et al., 2015). In his paper on the impact of front-end innovation activities on product performance, Markham shows that the Front-end success is the strongest independent predictor of all of the NPD performance 
variables. He further shows how the first stages of the innovation process are critical because the front-end performance impacts product success, time to market, market penetration, and financial performance (Markham, 2013).

In this context that stresses the relevance of the FEI, this review aims at providing an overview about how the FEI concept has been unfolding over the years by identifying the focus of the research conducted in this domain knowledge. We follow the integrative literature review approach as defined byTorraco, as "a form of research that reviews, critiques, and synthesizes representative literature on a topic in an integrated way such that new frameworks and perspectives on the topic are generated."(Torraco, 2005, p.356). As a result, this integrative literature review shows the diversity and depth of the topics approached in this field. The goal is to demonstrate that the FEI literature remains highly dispersed (Eliens and May, 2015) and that the FEI is comparatively less studied than the NPD and Commercialization phases (Koen et al., 2014).

This study offers an encompassing perspective by building on two FEI Reference Models. The analysis is based on the compilation, selection, and review of the content of 169 publications concerning the Front end of Innovation. The search included all papers published in SCOPUS until the end of 2015.

The analysis followed a framework that integrates two theoretical models, the socalled "New Concept Development Model" proposed by (Koen et al., 2002) and the "Three Phase Front End Model" proposed by (Khurana and Rosenthal, 1997, 1998).

The paper is organised into six sections. Following the introduction laid down under Section 1, section 2 offers a brief overview of the literature on the topic of the FEI. The research method is presented in Section 3, followed by the presentation of results in Section 4 and their discussion with the concluding remarks in Section 5. Section 6 tackles the limitations of the work.

\section{Literature review}

Innovation is an important issue for organisations and countries. Technological Innovation has a disruptive character that promotes differentiation for organisations, which may enable them to have a distinctive position in the competitive market (Schumpeter, 1988). It is worth pointing out that when we think about technology, we look at it as a means that can be used to accomplish a certain end (Eckhardt, 2013).

In fact, there are studies which suggest that innovation may lead organisations to a prominent position (Banbury and Michell, 1995). In this context, new products play an important role, as they may generate new revenues and new markets (Tidd et al., 2008).

Innovation stems from ideas that are the result of a creative or rational thinking process. This process may have the involvement of several actors, such as employees, customers, suppliers or universities organised as individuals or groups (Boeddrich, 2004). Moreover, innovation is a concept that depicts not only something that is new but also that is economically viable, technically feasible and expected to be successful in the market (Mueller and Thoring, 2012). 
Innovation management plays, therefore, an important role in companies seeking to find innovative products and business opportunities. This importance is, indeed, about learning how to find the solution that best suits the problem of turning ideas into a successful reality. Within specific organisational circumstances, organisations will always strive to do it the best possible way (Bessant, 2003).

FEI activities play, thus, a very important role in this process, as they may provide value and increase the amount and probability of success of the developed concepts aiming at future commercialization (Koen et al., 2002). The in-depth understanding of the Front End of Innovation can be seen as the ideal starting point for innovation, as FEI can foster the coordinated process of product or service concept development (Wagner, 2012).

Research shows that FEI optimization and improvement lead organizations to positive results by increasing chances of development of innovation (Boeddrich, 2004; Koen et al., 2014; Koen et al., 2014a; Markham, 2013; Stevens and Burley, 2004; Verworn et al., 2008; Williams et al., 2007).

Activities carried out in the FEI have a distinctive nature, being both experimental and often chaotic. In contrast, the NPD stage is more focused, disciplined and goal-orientated with a well-defined project plan (Koen et al., 2002). MontoyaWeiss and O' Driscoll (2000) refer to FFE (FEI) as unstructured and Ad-Hoc. Despite the "fuzziness" of this stage, the FEI is the foundation for the generation of successful New Product Development (NPD) (Martinsuo and Poskela, 2011).

FEI also brings about some challenges. Some authors highlight significant different approaches to FEI for promoting radical and incremental innovations in NPD projects (Reid and De Brentani, 2004). More recent work argues that there are no significant differences (Verworn et al., 2008). Another debate concerns the benefits of adopting a structured versus a non-structured approach for the FEI process. Recent research has shown the benefit of intensive initial planning and the process-oriented approach (Verworn et al., 2008; Markham, 2013). The literature review has further unveiled that most published works looking into FEI models and frameworks, include the four references highlighted in Table.

Table 1. FEI Reference works.

\begin{tabular}{lll}
\hline Year & Authors & Focus \\
\hline 1993 & Cooper, R. G. & $\begin{array}{l}\text { This work aims at a successful product innovation process, from idea to } \\
\text { launch. The first phases represent the FEl and make use of stage-gates. }\end{array}$ \\
\hline 1997 & $\begin{array}{l}\text { Khurana, A. } \\
\text { Rosenthal, S. R. }\end{array}$ & $\begin{array}{l}\text { It is a front-end approach that links business and product strategy with } \\
\text { product-specific decisions. }\end{array}$ \\
\hline 2001 & Koen et al. & $\begin{array}{l}\text { The aim of the work was to provide methods, tools, and techniques } \\
\text { suitable for managing the Front End of Innovation. Furthermore, the } \\
\text { authors envisioned the possibility of specifying a vision and a common } \\
\text { terminology for FEl. }\end{array}$ \\
\hline 2004 & $\begin{array}{l}\text { Rocus on disruptive innovation. A scheme based on the idea of a } \\
\text { reversed information flow from the outside world toward the } \\
\text { De Brgntani, U. }\end{array}$ & $\begin{array}{l}\text { orgation. Individuals who play important roles facilitate this flow. The } \\
\text { first interface is known as "boundary interface," followed by the } \\
\text { "gatekeeping interface" and concluded with the project interface. }\end{array}$
\end{tabular}


For Gaubinger and Rabl (2013) the four models most frequently cited in FEI literature are the "Stage Gate process" (Cooper, 1993); the "Three Phase Front End Model" (Khurana and Rosenthal, 1997); and the "New Concept Development Model" (Koen et al., 2002). Therefore, it can be said that the overview presented under Table 1 is by no means comprehensive; however, it does list important and seminal contributions to the conceptualization of the FEI. The next few paragraphs will briefly go through each one of these papers.

An important contribution from the Cooper's model (1993) regards the Concept Test occurring before the final assessment, thus representing the anticipation of important decisions. This model has received improvements over the time through the integration of both lean and agile approaches. The proposed Stagegate process "consists of a set of information-gathering stages followed by go/kill decision gates" (Cooper, 2008, p. 214).

The paper "Integrating the Fuzzy Front End of New Product Development" by (Khurana and Rosenthal, 1997) identifies the important role organisational strategy plays as a driving force in the innovation process. The authors propose a model focused on the linkage between business and product strategy. Moreover, they emphasise the importance of a well-planned portfolio; the existence of an enabling organisational structure; the need to adequately identify customer needs; and the development of a well-defined product concept as a means for a successful NPD.

There is an important contribution from Koen et al. (2002) with the New Concept Development Model. The aim of the work was to provide methods, tools, and techniques suitable for managing the FEI, although, these tools are likely to be selected and used in a heuristic manner (Achiche et al., 2013). The "NCD Model" proposed by Koen et al. (2002) is composed of three important parts, namely: The Engine, the Controllable Activity Elements, and the Influencing Factors. The first one is related to aspects such as Leadership, Culture and Business Strategy. The Key Elements (inner parts of the model) comprise the Opportunity Identification, the Opportunity Analysis, the Idea Generation and Enrichment, the Idea Selection, and the Concept Definition. At last, the influencing factors are those related to the internal and external environment, namely Organizational Capabilities and the Outside World. According to the authors, all these factors may influence the entire innovation process from the very beginning until the final commercialization phase.

The models proposed by Cooper (1988) and by Khurana and Rosenthal (1997) are linear schemes. Over the years, the Cooper's model has evolved and has gained an iterative nature. In turn, Koen et al. (2002) designed a model with a nature that is fundamentally iterative, trying to address the complexity of this phase.

In the last row of the table, Reid and De Brentani (2004) have been focusing on FEI for radical innovations. As a result, they have proposed a model that aims at dealing with risk more effectively and considering the complexity that arises in disruptive innovations. Their proposal has a major focus on decision-making points. This emphasis on decision making is valuable for organisations, as it provides a configuration that helps the flow of information, regarding the development of a new product. This theoretical model has received contributions and enhancements (De Brentani and Reid, 2012). 
These are seminal works focusing on the early stages of the innovation process. They aim at providing efficiency and efficacy for the FEI. Although valuable contributions have been made so far, there is still room for contributions to this domain of knowledge.

\section{$3 \quad$ Research method}

This research follows the so-called Integrative Literature Review Approach (Torraco, 2005). This strategy "is a form of a research that reviews, critiques, and synthesizes the representative literature on a topic in an integrated way so that new frameworks and perspectives on the topic are generated" (Torraco, 2005, p, 356). In other words, an integrative literature review for the FEI allows a summarised review of the topic, provides the means to draw a comprehensive picture of what has been studied so far in the scope of this theme, thus contributing to a consolidated and systematic overview of the area.

\subsection{Data collection procedures}

The data collection process was carried out from the Scopus database, a recognised multidisciplinary scientific database. In what concerns the choice of a database, as both Scopus and Web of Science offer quite similar functionalities and coverage (Öchsner, 2013), Scopus was chosen since this database exhibited the greatest number of active titles in February of 2014 (Scopus, 2014).

The search included papers published up to 2015. After the classification protocol was put in place, relevant works were found only from 1995 onwards. Results published before 1995 although being considered due to the use of the pair words "Front End" and "Innovation" addressed other contexts, not the management of the predevelopment phase of the innovation process. This search was conducted for the predefined subject areas listed by Scopus as follows:

Business, Management, and Accounting; Engineering; Computer Science; Decision Sciences; Economics, Econometrics, and Finance; Social Science; Material Science; Arts and Humanities; and, Psychology.

The following areas were excluded from the query:

Energy; Medicine; Chemical Engineering; Physics and Astronomy; Agricultural and Biological Science; Environmental Science; Chemistry; Earth and Planetary Sciences; Biochemistry, Genetics, and Molecular Biology; Health Professions; Nursing; Pharmacology, Toxicology, and Pharmaceutics; Immunology and Microbiology; Mathematics; and, Neuroscience.

The search has only considered documents classified as "article." This was done to ensure that all selected works have gone through a peer review process. The database query was made using the following type of field: "Article Title, Abstract, and Keyword." To widen the results of the query the proximity indicator filter was used. For instance, W/n "within." In this case, the query was set up as follows:

"Front end" of W/8 innovation

The proximity indicator searches for "innovation" within the following eight 
words in the text. This search configuration leads to a result with a larger number of selected articles related to the research goal.

Figure 1 illustrates the reason why the expression "front end" was used among other possible denominations for this concept. The amount of results found explains that the term "front end" is widely used, as compared with other possible formulations.

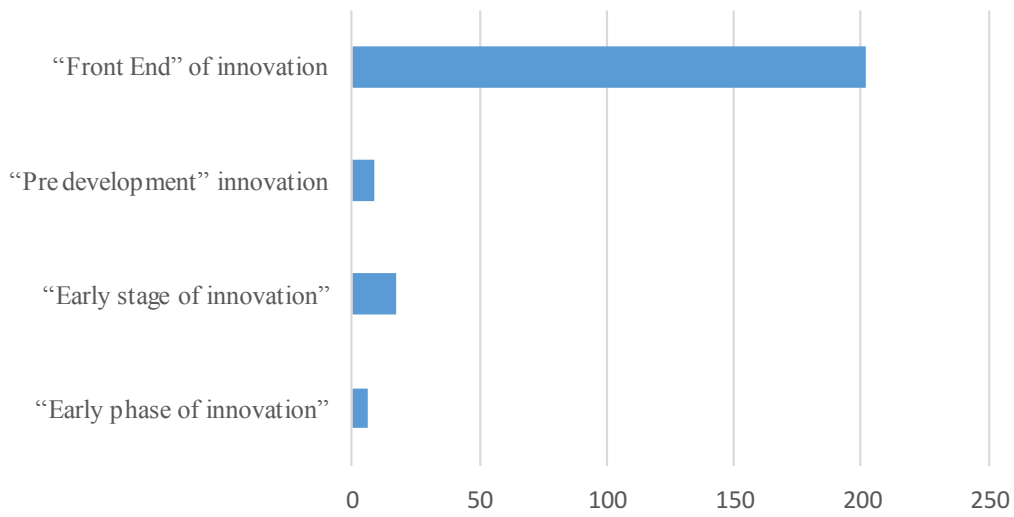

Fig. 1. Results found concerning the possible nomenclatures to be used in the query.

The term "Fuzzy Front End" is contemplated in the use of the expression "Front End." Moreover, the Scopus database makes no difference in what regards the use of hyphen for "front-end" or "front end."

The authors have classified the works according to their contents. Search results were further analysed and classified to select only those papers dealing with topics related to the FEI. In some papers, the expression "Front End (...) Innovation" was not related to FEI but to other issues such as topics addressing the role of design, organisational Front End activities, and Front End engineering concepts. Additionally, papers with no abstract or written in a language other than English were not considered. After the classification procedures, in the final sample includes a total of 169 titles.

\subsection{Data collection}

The theoretical framework for analysing the results was based on the model proposed by Koen et al. (2002) "New Concept Development" (NCD) (Figure 2). This approach was chosen as this is the method accepted and used by the Product Development Management Association. For the sake of providing an additional perspective of analysis, the findings were also plotted into the "Three Phase Front End Model" (Khurana and Rosenthal, 1997, 1998). This model was selected as it provides a wide perspective on the FEI processes while keeping the same definition for "idea" and "opportunity" as the NCD Model.

The 169 articles were organised in an electronic spreadsheet. They were systematically organised according to their publication year, title, abstract and publication information. The results were categorised taking into consideration the contents in the abstract. The content of each paper was plotted into an ndimensional classification space featuring components of two frameworks: the 
"NCD Model"; and the "Three Phase Front End Model." It must be stressed that some papers could be classified under more than one category. These cases were classified considering the dominant approach put forward by the work. For example: a research publication on the "process of generating new-market disruptive innovation (NDI) ideas for products, driven by design and resources" would be classified as "Idea Generation and Enrichment" (IGE) in the "NCD Model". Moreover, as "Pre-phase Zero" (PP0) in the "The Three Phase Front End Model". However, it could have been classified as well into "Organisational Capabilities" (OC) / "Product Development Organization" (PDO) respectively in the two reference models.

Out of the total 169 articles, 44 papers offered contributions for the FEI regarded as a framework, a model, a process, a tool or even a methodology.

The analytical categories used in this research are shown in Figures 2 and 3.

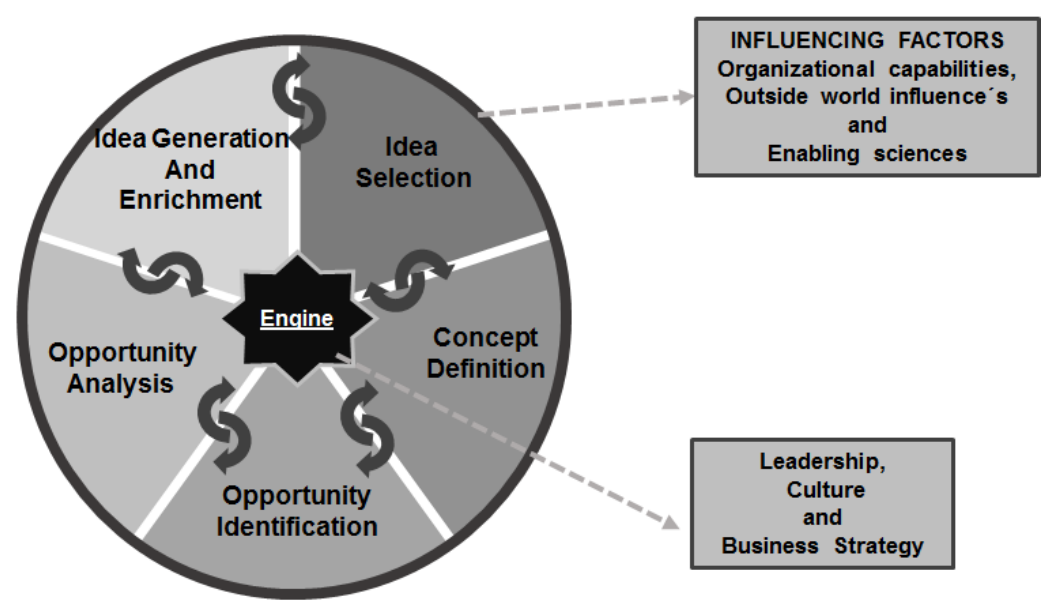

Fig. 2. NCD Model as categories of analysis - Adapted from Koen et al. (2002)

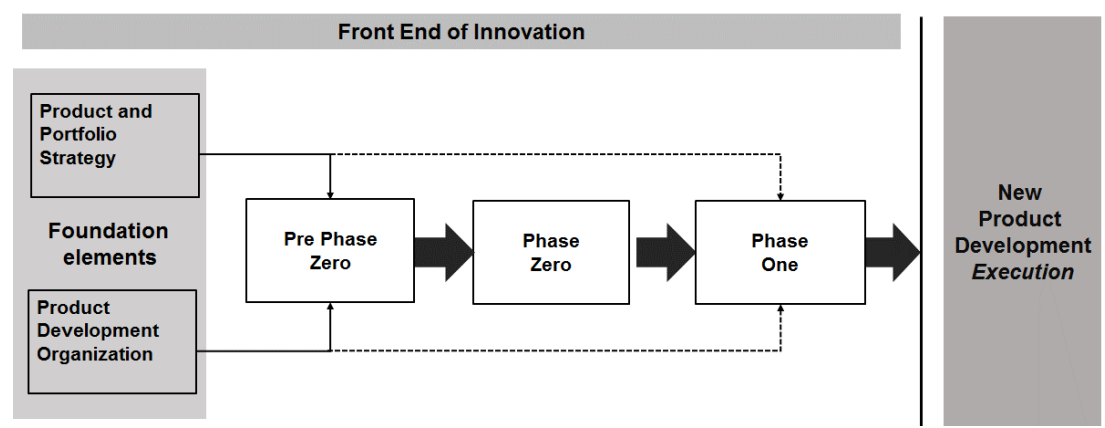

Fig. 3. Three Phase Model of the Front End of Innovation as categories of analysis Adapted from Khurana and Rosenthal (1998)

The coding for the categories of analysis used in the classification protocols is illustrated in Table 2 . The acronyms listed below will be used in the classification tables in the following section. 
Table 2. List of acronyms used for the categories of analysis

\begin{tabular}{lc}
\hline NCD Model & ACRONYMS \\
\hline Leadership & LD \\
Culture & CULT \\
Business Strategy & BS \\
Idea Generation and Enrichment & IGE \\
Idea Selection & IS \\
Opportunity Identification & OI \\
Opportunity Analysis & OA \\
Concept Definition & CD \\
Organizational Capabilities & OC \\
Outside World Influence's (Customer and competitor influences) & OWI \\
Enabling Sciences & EST \\
The Three Phase model of the Front End of Innovation & \\
Product and Portfolio Strategy - PPS & PPS \\
Product Development Organization (Structure, Roles, Incentives and Norms) & PDO \\
Pre-phase zero (Preliminary Opportunity Identification, Idea Generation, Market and & PP0 \\
Technology Analysis) & P0 \\
Phase zero (Product Concept and Definition) & P1 \\
Phase one (Feasibility and Project Planning) &
\end{tabular}

\section{$4 \quad$ Results}

The analysis shows that increasing attention has been paid to the FEI in recent years. The term "Fuzzy Front End" was coined at the beginning of the nineties, but it has only started to be considered as a consistently increasing trend in the field since 2006. 2012 was identified as the year with the highest number of publications, as illustrated in Figure 4.

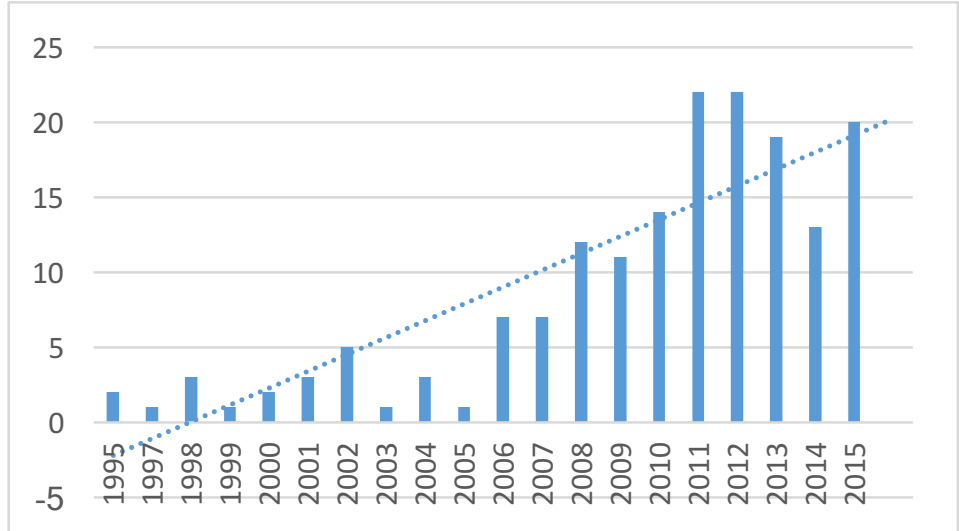

Fig. 4. FEI works from 1995 to 2015

Figure 4 illustrates the trend of the 169 publications along the years, depicting a growing number of published papers in this domain of knowledge. It should be noted that this analysis makes no distinction between the type of innovation (incremental or radical) discussed in each paper. 


\subsection{Analysis Projected over the NCD Model}

The multidisciplinary nature of this field of knowledge leads to a scenario where one has a broad number of research topics, some recurrent in many papers, and other topics receiving less attention. Table 3 displays the number of publications per year (line) and per research topic (column).

Table 3. Incidence of NCD Model's elements addressed per year from 1995-2015

\begin{tabular}{|c|c|c|c|c|c|c|c|c|c|c|c|c|}
\hline Year & BS & $C D$ & CULT & EST & IGE & IS & LD & $O A$ & $O C$ & 이 & ow & Total \\
\hline 1995 & & & & & 1 & & & & 1 & & & 2 \\
\hline 1997 & & & 1 & & & & & & & & & 1 \\
\hline 1998 & & & & & 1 & & & & 2 & & & 3 \\
\hline 1999 & & & & & & & & & 1 & & & 1 \\
\hline 2000 & & & & 1 & & & & & 1 & & & 2 \\
\hline 2001 & 1 & & & & & & & 1 & 1 & & & 3 \\
\hline 2002 & & & & 1 & 1 & & & & 3 & & & 5 \\
\hline 2003 & & & & & & & & & 1 & & & 1 \\
\hline 2004 & & & & & & & & & 3 & & & 3 \\
\hline 2006 & 1 & 2 & & & & & & & 3 & 1 & & 7 \\
\hline 2007 & 1 & 3 & & & & & & & 1 & 2 & & 7 \\
\hline 2008 & 1 & 3 & & & 3 & & & 1 & 3 & 1 & & 12 \\
\hline 2009 & 2 & 4 & & 1 & 1 & & & 1 & 1 & & 1 & 11 \\
\hline 2010 & 2 & 2 & & & 2 & & & 1 & 4 & 2 & 1 & 14 \\
\hline 2011 & 4 & 3 & 1 & & 3 & 1 & & & 6 & 2 & 2 & 22 \\
\hline 2012 & 3 & 1 & 1 & & 6 & 1 & & 1 & 6 & 2 & 1 & 22 \\
\hline 2013 & 1 & 6 & 1 & & 6 & & 1 & 1 & 1 & 2 & & 19 \\
\hline 2014 & & & & & 4 & & & & 6 & 2 & 1 & 13 \\
\hline 2015 & 1 & 1 & & 1 & 5 & & & & 8 & 4 & & 20 \\
\hline Total & 17 & 25 & 4 & 4 & 33 & 2 & 1 & 6 & 53 & 18 & 6 & 169 \\
\hline
\end{tabular}

Although the number of papers has been increasing over time, topics such as Leadership, Idea Selection, Enabling Sciences and Culture have only received limited attention. As illustrated, the findings suggest that some areas have received more attention in quantitative terms. Such is the case of OC Organisational Capabilities. OC represents a big umbrella, covering topics varying from structure, resources, capabilities and competencies to processes, norms and efficiency, which may partly explain its high number of hits. Idea Generation and Enrichment (IGE) is also quite encompassing, as it includes: the means, incentives, methods, tools, techniques and resources used for IGE activities. 
Another topic that received important contributions is the CD - Concept Definition. This activity involves an important task in the process, as it represents the input for the New Product Development and Commercialization phases.

It is now relevant to consider the structure of the NCD Model to analyse the results. Table 4 shows the configuration of the NCD building on the definitions proposed by Koen et al. (2002). In this context, results show that:

- More attention was given to the OC - Organisational Capabilities, which is part of the Influencing Factors in the NCD Model.

- Controllable Activities are receiving a broader attention in FEI publications (related to topics such as Idea Generation and Enrichment, Concept Definition and Opportunity Identification).

Table 4. NCD Model's composition

\begin{tabular}{ll}
\hline Part of the Model & Content addressed \\
\hline \multirow{3}{*}{ Engine } & Leadership - LD \\
& Culture - CULT \\
& Business Strategy - BS \\
\hline & Idea Generation and Enrichment - IGE \\
Idea Selection - IS \\
Elements & Opportunity Identification - OI \\
(Controllable Activities) & Opportunity Analysis - OA \\
& Concept Definition - CD \\
\hline \multirow{3}{*}{ Influencing Factors } & Organisational Capabilities - OC \\
& Outside World Influence's - OW \\
& Enabling Sciences and Technologies -EST \\
\hline
\end{tabular}

The part of the model that has received less attention regarding the number of publications was the Engine, addressing topics such as Leadership, Culture and Business Strategy. The relevance of these topics however has been addressed in a recent study (Koen, Bertels, and Kleinschmidt, 2014) where 197 empirical cases on successful Front End practices were analysed. The study highlighted the importance of senior management commitment, vision, strategy, and resources.

As the major contribution regarding the volume of publications is from 2006, Figure 5 illustrates the inner parts of the "NCD Model" showing the number of publications over the last years. 


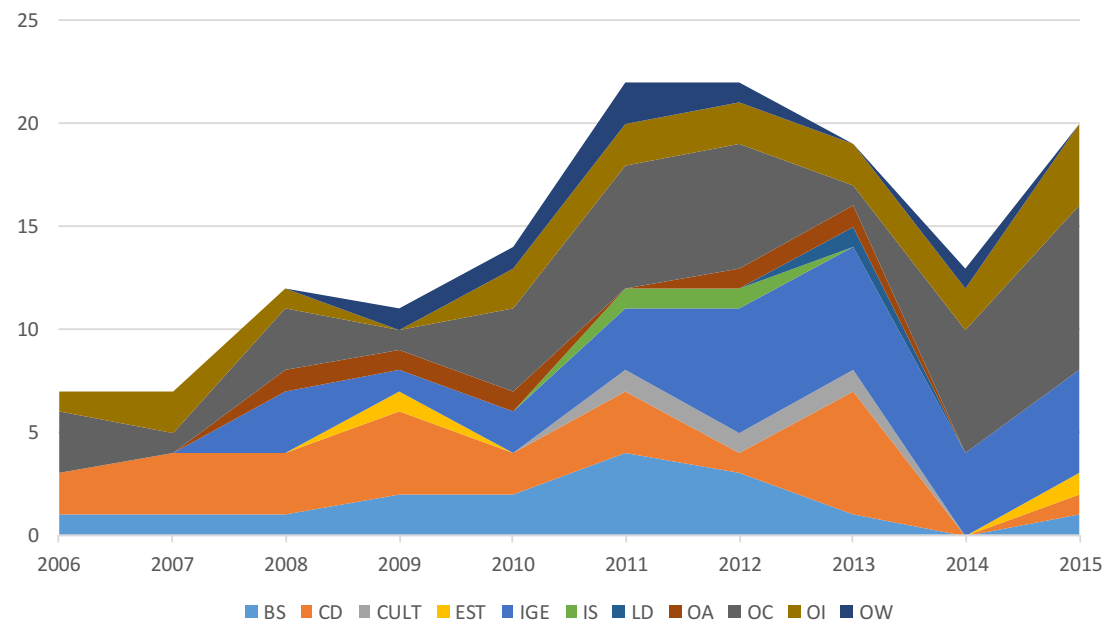

Fig. 5. Inner parts of the NCD Model addressed per year, 2006 - 2015

\subsection{Analysis Projected over the Three Phase Front End Model}

In order to provide a comparative visualisation of the analysed data, the 169 papers were also classified following the framework of analysis proposed by Khurana and Rosenthal (1998). In this approach, the FEI activities include product strategy formulation and communication, opportunity identification and assessment, idea generation, product definition, project planning and executive reviews. The "Three Phase Front End Model" (Khurana and Rosenthal, 1997, 1998) is organised as illustrated in Table 5.

Table 5. The Three Phase Front End Model

\begin{tabular}{ll}
\hline Concept & Responsibilities \\
\hline Foundation & Product and Portfolio Strategy - PPS \\
Elements & Product Development Organization - PDO \\
\hline & Pre-phase zero (Preliminary Opportunity Identification, Market and Technology \\
Front End & Analysis) - PP0 \\
& Phase zero (Product Concept and Definition) - P0 \\
& Phase one (Feasibility and Project Planning) - P1 \\
\hline
\end{tabular}

This model emphasises the organisational alignment and the product strategy. The authors further highlight the great value of the interrelationship between activities, which are considered as important as the activities themselves (Khurana and Rosenthal, 1997). Taking into account this framework of analysis, the result of the analysis of the 169 papers is shown in Table 6. 
Table 6. Finding results according to the Three Phase Front End Model

\begin{tabular}{|c|c|c|c|c|c|c|}
\hline Year & Po & P1 & PDO & PPO & PPS & Total \\
\hline 1995 & & & 1 & 1 & & 2 \\
\hline 1997 & & & 1 & & & 1 \\
\hline 1998 & & & 2 & 1 & & 3 \\
\hline 1999 & & 1 & & & & 1 \\
\hline 2000 & & & 1 & & 1 & 2 \\
\hline 2001 & & & 1 & 1 & 1 & 3 \\
\hline 2002 & & & 3 & 2 & & 5 \\
\hline 2003 & & & 1 & & & 1 \\
\hline 2004 & & & 3 & & & 3 \\
\hline 2005 & & & 1 & & & 1 \\
\hline 2006 & 2 & 2 & 2 & & 1 & 7 \\
\hline 2007 & 2 & 1 & 1 & 2 & 1 & 7 \\
\hline 2008 & & 3 & 2 & 5 & 2 & 12 \\
\hline 2009 & 2 & 4 & & 2 & 3 & 11 \\
\hline 2010 & 1 & & 5 & 5 & 3 & 14 \\
\hline 2011 & 3 & 2 & 8 & 4 & 5 & 22 \\
\hline 2012 & 2 & & 9 & 9 & 2 & 22 \\
\hline 2013 & 6 & & 7 & 6 & & 19 \\
\hline 2014 & 1 & 4 & 5 & 3 & & 13 \\
\hline 2015 & 4 & 4 & 5 & 6 & 1 & 20 \\
\hline Total & 23 & 21 & 59 & 47 & 20 & 169 \\
\hline
\end{tabular}

Based on these results we can state that the parts of the model that have received more attention from 1995 to 2015 were respectively PDO (Product Development Organization) and PP0 (Pre-phase zero). The Product Development Organization is related to an organisation structure, roles, incentives, and norms, which is an important support for the efficiency of the FEI. PP0 is responsible for performing Preliminary Opportunity Identification, Market, and Technology Analysis. In this case, the two most expressive concepts regarding the number of contributions are representing the two parts of the Model, respectively the Foundation Elements and the Front End itself.

Concerning the areas that have received less attention, we can mention Product and Portfolio Strategy (PPS), P1 (Phase One) and P0 (Phase zero) which depict a low number of publications. It is in Phase One that feasibility issues and project planning are dealt with. Moreover, it is in Phase Zero that the product concept and definition are shaped. On the other hand, Product and Portfolio Strategy address the need of a clear product strategy and a well-planned portfolio of new products.

Figure 6 illustrates the inner parts of the "Three Phase Front End Model" (Khurana and Rosenthal, 1997, 1998) depicting attention received over the last years. 


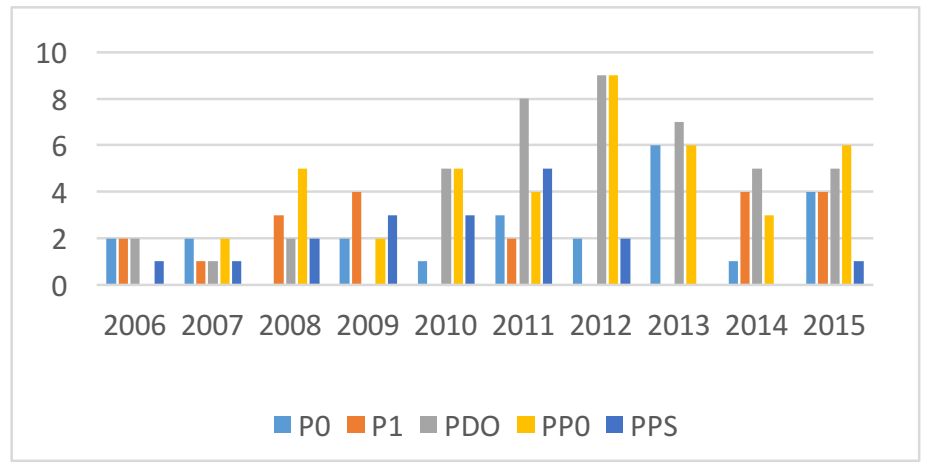

Fig. 6. FEI publications through the lens of the Three Phase Front End Model

\section{Discussion \& Conclusion}

The evolution in the number of publications over time reveals the emergence of the FEI in recent years. Until 2005 this topic received limited attention. In 2006 the research focus started to widen with the first publications on the topic of "Opportunity Identification" (OI). Special attention must be be given to years 2011, 2012 and 2013 that show an increase in the number of papers and the broadening of research perspectives, thus bringing more diversity of contributions to the FEI research (see Table 3 and Figure 4). This could suggest that an in-depth understanding of the FEI phenomena may have fostered the need to open up research into new directions.

In the context of the NCD Model classification framework, the substantial lack of contributions to topics related to Leadership, Enabling Sciences and Technologies, Culture, Idea Selection and Opportunity Analysis is clear. The relative weight of these components is illustrated in Figure 7 as percentages, where Leadership and Idea Selection get only $1 \%$, the lowest value.

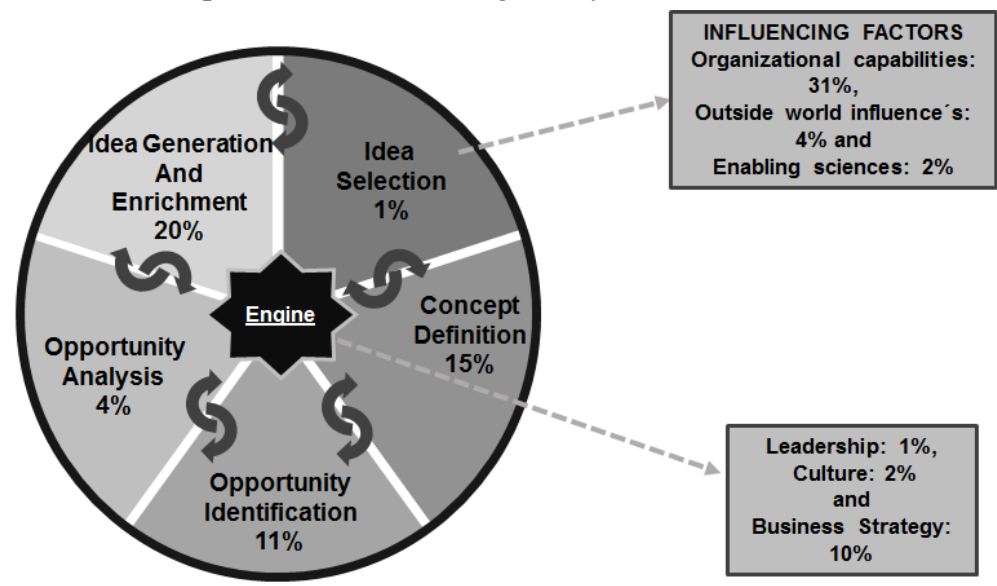

Fig. 7. Research findings through the lens of the NCD Model

As regards to the "Three Phase Front End Model," results show that the area with less emphasis is "Phase One" covering topics related to the analysis and decisions 
about the feasibility of the developed concept; and the issues related to project planning. Figure 8 pictures the relative weight of the different "Three Phase Front End Model" components.

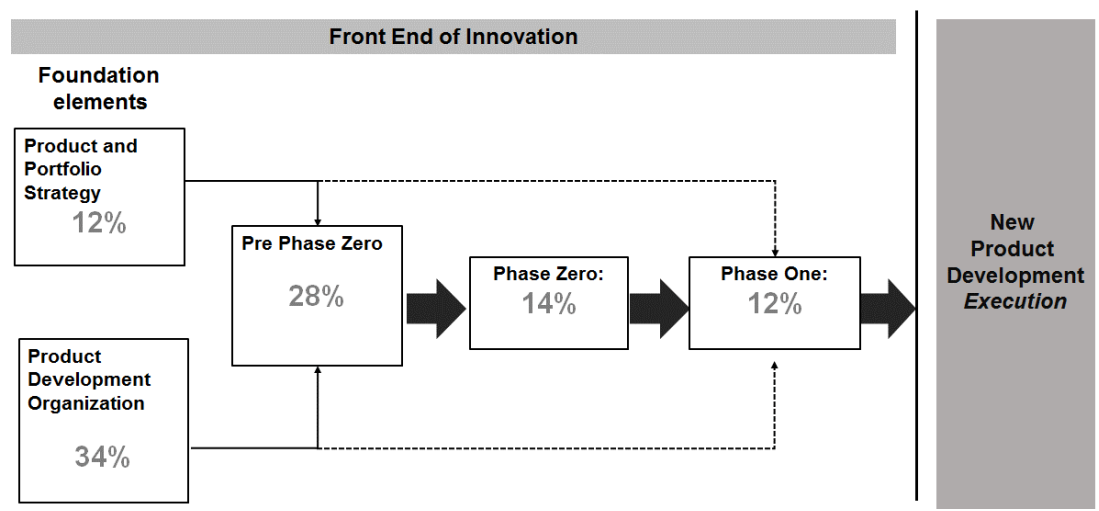

Fig. 8. Research findings through the lens of the Three Phase Front End Model

In both models, the topics addressing organisational issues were the ones that received more attention. Organisational competencies are indeed important as they may be considered as the means of providing the basis for FEI activities.

The findings show that the FEI has received more attention in recent years. Concerning the "NCD model", the parts more frequently addressed in the research were "Organisational Capabilities", "Idea Generation and Enrichment", and "Opportunity Identification". These results are aligned with the findings resulting from the projection into the "Three Phase Front End Model" that reveal more attention given to "Product Development Organisation" (PDO) and "PrePhase Zero" (PP0). This latter phase covers the "Preliminary Opportunity Identification," and the "Market and Technology Analysis".

The topics that were addressed less frequently in the literature in the context of the "NCD Model" were Leadership, Idea Selection, and Enabling Sciences. These topics are not explicitly handled in the "Three Phase Front End Model" and would likely fall into "Product Development Organisation" (PDO). The higher granularity of the "NCD Model" leads to a less concentration of publications per topic, in contrast to Table 6 where the lower granularity of the "Three Phase Front End Model" leads to a less unbalanced distribution of publications in each phase. Evidence shows that the FEI has received greater attention in recent years both regarding depth and number of publications. In this context, and beyond the analysis conducted in this literature research, there are still pending gaps, namely:

- Regarding the applicability of modern approaches in FEI, Gonzáles (2014) uncovered insufficient findings for the use of agile project management;

- There is little research focusing on the Management of this phase of the innovation process (Robins and O'Gorman, 2015);

- Eliens and May (2015) highlight the high number of publications related to tools and methodologies. Although these works bring some insights to the field, most of the contributions address the effect that a specific tool has on a particular FEI process. As a result, many publications do not generate a substantial amount of knowledge for the FEI research field as a 
whole. There is a lack of contributions regarding the so-called process activity models (mapping of the entire FEI process).

- The FEI requires a holistic approach and an innovative mindset. Possible trends worthy of investment are related to the use of ICT technologies. For instance "software to explore and track technological trends, nethnographic procedures to observe user behaviour and collect user ideas online, technical advancements to increase the validity of virtual prototyping" (Gassmann and Schweitzer, 2013, p. 302). An example of such research effort may be found in Barradas and Rodrigues (2016).

The "front-end performance favourably and independently impacts overall product success, time to market, market penetration, and financial performance" (Markham, 2013, p. 77). This stresses the relevance of building a comprehensive body knowledge in the area of the Front-End Innovation as a multi-disciplinary research domain. It would be beneficial if future research could promote a holistic understanding of the Management of the entire Front-End Innovation processes, across the different "NCD Model" perspectives, thus resulting in an increased innovation process performance. This might be particularly helpful for Entrepreneurs and Companies alike, who seek to improve their innovation capabilities.

\section{$6 \quad$ Limitations of this research}

The limitations of this research result from:

- The restrictions on the survey conducted in the database related to the use of the term "Front End" of Innovation which may have left out some other terms that represent this phase of the innovation process.

- The survey was performed in one database only; however, comparing Scopus with Web of Science, the former is the one with the largest breadth of coverage and number of journals (Öchsner, 2013).

- The analysis did not take into account environmental issues, organisational structure and organisational decision making (Child, 1972).

- The classification was made using the "NCD model" and "Three Phase Front End Model" frameworks and represents the best fit resulting from the author's perspective. Despite this, the author tried to reduce possible causes for any interpretation bias. To this end, this classification was reviewed in three different moments in time separated by a period of 3 to 4 months. All the classification revisions were made against the same framework of analysis. In future analysis, it could be interesting to use an approach based on a consensus classification process.

Acknowledgments. This work benefited from the financial support of the Coordenação de Aperfeiçoamento de Pessoal de Nível Superior-CAPES Brazil.

\section{$7 \quad$ References}

Achiche, S., Appio, F. P., McAloone, T. C., and Di Minin, A. (2013). Fuzzy 
decision support for tools selection in the core front end activities of new product development. Res Eng Design, 24:1-18, http://doi.org/10.1007/s00163-012-0130-4

Banbury, C. M.; Mitchell. W. (1995). The effect of introducing important incremental innovations on market share and business survival. Strategic Management Journal, Vol. 16, p. 161-182.

Barradas, L. C; Rodrigues, E. M. (2016). Deriving an ontology for knowledge management in collaborative innovation networks. Int. J. Innovation and Learning, Vol. 19, No. 3.

Bessant, J. (2003). Challenges in Innovation Management. The International Handbook on Innovation, (December 2003), 761-774. http://doi.org/10.1016/B978-008044198-6/50052-8

Boeddrich, H.-J. (2004). Ideas in the Workplace: A New Approach Towards Organizing the Fuzzy Front End of the Innovation Process. Creativity and Innovation Management, 13(4), 274-285. http://doi.org/10.1111/j.09631690.2004.00316.x

Child, John (1972). Organizational structure, environment and performance: the role of strategic choice. Sociology. January, vol. 6 no. 1, 1-22.

Cooper, R. G. (1993). Winning at new products: accelerating the process from idea to launch. New York, Addison-Wesley, 1993.

Cooper. R. G. (2008). The Stage-Gate Idea-to-Launch Process-Update, What's New and NexGen Systems. Journal of Product Innovation Management, Volume 25, Number 3, May 2008, pp 213-232.

De Brentani, U., Reid, S.E. (2012). The fuzzy front-end of discontinuous innovation: Insights for research and management. Journal of Product Innovation Management, 29 (1), pp. 70-87.

Eckhardt, J. T. (2013). Opportunities in business model research. Strategic Organization, 11(4), 412-417. http://doi.org/10.1177/1476127013511059

Eliens, L., and May, A. L. X. (2015). Master Program in Innovation and Technological Entrepreneurship Disentangling the fuzzy front-end: an integrative literature review Luuk Eliens, (May).

Evanschitzky, H., Eisend, M., Calantone, R. J., and Jiang, Y. (2012). Success Factors of Product Innovation: An Updated Meta-Analysis. Journal of Product Innovation Management, 29(1994), 21-37. http://doi.org/10.1111/j.1540-5885.2012.00964.x

Gassmann, O, Schweitzer, F. (2013). Management of the Fuzzy Front End of Innovation. SpringerLink. Springer International Publishing Switzerland.

Gaubinger, K., Rabl, M. (2013). Management of the Fuzzy Front End of Innovation. Gassmann, O, Schweitzer, F. (Eds). Chapter: Structuring the Front End of Innovation. SpringerLink. Springer International Publishing Switzerland, p. 15-30.

Gonzáles, W. (2014). Applying agile project management to predevelopment stages of innovation. International Journal of Innovation and Technology Management, v. 11, p. 1450020-1-1450020-22.

Khurana, A., and Rosenthal, S. (1997). New product development. Journal of 
Product and Brand Management, 5(5), 1-56. http://doi.org/10.1108/10610421199600002

Khurana, A., and Rosenthal, S. (1998). Khurana and Rosenthal.Pdf. Journal Product Innovation Management, 15, 57-74.

Kock, A., Heising, W. and Gemünden, H. G. (2015), How Ideation Portfolio Management Influences Front-End Success. J Prod Innov Manag, 32, 539555.

Koen, P. A., Bertels, H. M. J., and Kleinschmidt, E. J. (2014). Managing the Front End of Innovation-Part I. Research Technology Management, 57(2), 34-44. http://doi.org/10.5437/08956308X5702145

Koen, P. A., Bertels, H. M. J., and Kleinschmidt, E. J. (2014a). Managing the Front End of Innovation-Part Results from a Three-Year Study, (June), 25-36. http://doi.org/10.5437/08956308X5703199

Koen, P., Ajamian, G. M., Boyce, S., Clamen, A., Fisher, E., Fountoulakis, S., ... Seibert, R. (2002). Fuzzy Front End: Effective Methods, Tools, and Techniques. Industrial Research, 5-35. Retrieved from http://www.stevens.edu/cce/NEW/PDFs/FuzzyFrontEnd_Old.pdfNEW/PD Fs/FuzzyFrontEnd_Old.pdf

Markham, S. K. (2013). The impact of front-end innovation activities on product performance. Journal of Product Innovation Management, 30(SUPPL 1), 77-92. http://doi.org/10.1111/jpim.12065

Martinsuo, M., and Poskela, J. (2011). Use of evaluation criteria and innovation performance in the front end of innovation BT - Special Issue from the PDMA and EIASM International Research Conference on New Product Development, Murcia, Spain, June 2010. Journal of Product Innovation Management, 28(6), 896-914. http://doi.org/10.1111/j.15405885.2011.00844.x

Mueller, R. M., and Thoring, K. (2012). Design Thinking Vs Lean Startup: A Comparison of Two Userdriven Innovation Strategies. Proceedings of 2012 International Design Management Research Conference, (October), 151161.

Öchsner, A. (2013). Introduction to scientific publishing: backgrounds, concepts, strategies. Heidelberg: Springer.

Reid, S. E., De Brentani, U. (2004). The fuzzy front end of new product development for discontinuous innovations: A theoretical model. Journal of Product Innovation Management, 21 (3): 170-84.

Robbins, P.; O'Gorman, C. (2015). Innovating the innovation process: an organisational experiment in global pharma pursuing radical innovation. $R \& D$ Management, Vol. 45, Issue 1, pages 76-93.

Schumpeter, J. A. (1988). A teoria do desenvolvimento econômico. São Paulo: Nova Cultural.

Scopus. (2014). Content coverage guide. Elsevier.

Stevens, G. A., and Burley, J. (2004). Piloting the rocket of radical innovation. IEEE Engineering Management Review, 32(3), 111-122. http://doi.org/10.1109/EMR.2004.25114 
Tidd, J.; et al. (2008). Gestão da inovação. $3^{\text {a }}$ Ed. Porto Alegre: Bookman.

Tidd, J. (2001). Innovation management in context: environment, organization and performance. International Journal of Management Reviews, 3(3), 169183. http://doi.org/10.1111/1468-2370.00062

Torraco, R.J. (2005). "Writing integrative Literature Reviews: Guidelines and Examples", Human Resource Development Review, 4(3), p. 356-367.

Verworn, B., Herstatt, C., and Nagahira, A. (2008). The fuzzy front end of Japanese new product development projects: Impact on success and differences between incremental and radical projects. $R$ and D Management, 38(1), 1-19. http://doi.org/10.1111/j.1467-9310.2007.00492.x

Wagner, S. M. (2012). Tapping Supplier Innovation. Journal of Supply Chain Management, 48(2), 37-52. http://doi.org/10.1111/j.1745493X.2011.03258.x

Williams, M. A., Kochhar, A. K., and Tennant, C. (2007). An object-oriented reference model of the fuzzy front end of the new product introduction process. International Journal of Advanced Manufacturing Technology, 34(7/8), 826-841. http://doi.org/10.1007/s00170-006-0645-9 